Pesq. Vet. Bras. 35(2):105-109, fevereiro 2015 DOI: 10.1590/S0100-736X2015000200001

\title{
Ação dos desinfetantes sobre a adesão e biofilme consolidado de Staphylococcus spp. ${ }^{1}$
}

INDEX TERMS: Staphylococcus spp., teat dipping, disinfectant, mastitis, prevention.

RESUMO.- Staphylococcus spp. são reconhecidos como importantes causadores de mastites em rebanhos leiteiros. Esses micro-organismos têm a capacidade de produzir uma estrutura denominada biofilme, que é responsável pela sobrevivência e muitas vezes pela resistência a ação de produtos desinfetantes e as demais condições adversas. Neste trabalho avaliou-se a ação de dois produtos pós-dipping a base de iodo $(0,7 \%)$ e clorexidine $(2,0 \%)$ sobre a adesão de Staphylococcus coagulase positiva (SCP) e Staphylococcus coagulase negativa (SCN) isolados de casos de mastite subclínica, e também sobre biofilmes pré formados a partir destes isolados. Os produtos testados apresentaram uma alta redução na taxa de adesão de todos os isolados. No entanto, a ação sobre os biofilmes consolidados

\footnotetext{
${ }^{1}$ Recebido em 16 de agosto de 2014.

Aceito para publicação em 30 de dezembro de 2014.

${ }^{2}$ Departamento de Medicina Veterinária Preventiva, Universidade Federal de Santa Maria (UFSM), Av. Roraima 1000, Santa Maria, RS 97105-900, Brasil.*Autor para correspondência: agueda.vargas@gmail.com

${ }^{3}$ Laboratório de Microbiologia e Imunologia Animal, Universidade Federal do Vale do São Francisco (Univasf), Rodovia BR-407 Km 12, Lote 543, Projeto de Irrigação Nilo Coelho s/n C1, Petrolina, PE 56300-000, Brasil.
}

só foi estatisticamente significativa sobre os SCN. Assim, ressalta-se a importância dos programas sanitários a fim de prevenir a formação de biofilmes e diminuir as fontes de contaminação da glândula mamaria em sistemas de produção leiteira.

TERMOS DE INDEXACAO: Staphylococcus spp., pós-dipping, desinfetantes, mastite, prevenção.

\section{INTRODUÇÃO}

A mastite infecciosa bovina é uma enfermidade associada à redução da produção e alterações na composição do leite, bem como ao descarte de animais (Barlow 2011). Os micro-organismos de origem contagiosa são os mais prevalentes em casos de mastite bovina e, entre esses, o genero Staphylococcus destaca-se por estar frequentemente associado a casos clínicos e subclínicos da enfermidade (Sá et al. 2004). São muitos os fatores de risco envolvidos na ocorrência de mastite em rebanhos leiteiros. Destacamos neste estudo a exposição da superfície dos tetos aos micro-organismos patogênicos contagiosos, os quais são transmitidos de animais infectados para não infectados durante o processo de ordenha (Amaral et al. 2004). 
O uso de produtos desinfetantes no pós-dipping é uma estratégia de controle de mastites contagiosas, principalmente aquelas causadas por Staphylococcus aureus e Streptococcus agalactiae (Santos \& Fonseca 2007) e garante, além da desinfecção, a formação de uma barreira física contra infecções, mesmo várias horas após sua aplicação (Edinger et al. 2000). Estudos já demonstraram a importância do uso do pós-dipping na redução da incidência de novas infecções intramamárias causadas por Staphylococcus spp. e outros patógenos relacionados a casos de mastites, bem como a diminuição da contagem de células somáticas (Galton 2004, Boddie \& Nickerson 2002). Staphylococcus spp. são reconhecidamente a causa mais frequente de infecções associadas a biofilmes, especialmente devido ao fato de serem agentes comensais, presentes na pele e superfícies mucosas (Otto 2008).

Os biofilmes são comunidades bacterianas, envoltas por uma matriz polimérica extracelular (Stepanovic et al. 2007). A formação do biofilme inicia com a adesão da célula bacteriana na superfície, seguida da sua maturação, ruptura e dispersão (Vermelho et al. 2007). Sabe-se que S. aureus e S. epidermidis, oriundos de casos de mastite, possuem alta capacidade de adesão em superfícies abióticas, formando, posteriormente, biofilmes altamente organizados (Oliveira et al. 2006). Tendo em vista a importância da adesão no processo de colonização e invasão de micro-organismos patogênicos, o uso in vitro de antimicrobianos na sua prevenção está muito bem documentado (Pagano et al. 2004).

Estudos têm demonstrado a eficácia de desinfetantes frente aos Staphylococcus spp. isolados de leite, sendo bem determinado que concentrações de iodo acima de $0,5 \%$ e clorexidine a $2 \%$ exercem atividade bactericida frente a esses micro-organismos (Pedrini \& Margatho 2003, Medeiros et al. 2009, Ramalho et al. 2012). Porém, devido às variações no perfil de suscetibilidade de células bacterianas frente a desinfetantes, é necessária uma avaliação periódica destes produtos para que não haja comprometimento dos programas de controle de mastite bovina causadas por Staphylococcus spp. (Medeiros et al. 2009). Além disso, estudos avaliando a ação destes produtos sobre a adesão e biofilme consolidado de Staphylococcus spp. isolados de leite ainda não foram logrados. Com base no exposto acima, o presente estudo buscou avaliar a ação de clorexidine $(2 \%)$ e iodo $(0,7 \%)$ na adesão de células livres de Staphylococcus coagulase positiva (SCP) e Staphylococcus coagulase negativa (SCN), bem como sobre seus respectivos biofilmes consolidados.

\section{MATERIAL E MÉTODOS}

Isolados bacterianos. Amostras individuais, colhidas assepticamente, de leite de vacas pertencentes a duas propriedades leiteiras de Santa Maria - RS foram semeadas em ágar sangue ovino $5 \%$ e incubadas em aerobiose a $37^{\circ} \mathrm{C}$ durante 48 horas. Colônias sugestivas de Staphylococcus spp. foram caracterizadas fenotipicamente conforme descrito por Quinn et al. (1994). Posteriormente, realizou-se o teste de coagulase conforme MacFaddin (2000). Para este estudo, foram selecionados 16 isolados de Staphylococcus spp., oito coagulase positiva, provenientes de uma propriedade com histórico de mastite bovina por SCP; e oito coagulase negativa, provenientes de outra propriedade.

Caracterização dos isolados quanto à produção de biofilmes. A caracterização dos isolados foi realizada de acordo com
Rodrigues et al. (2010). Colônias isoladas de Staphylococcus spp. foram inoculadas em $3 \mathrm{ml}$ de Tryptone Soya Broth (TSB) até turvação de $0.5 \mathrm{MacF}$ arland e incubadas a $37^{\circ} \mathrm{C}$ por 24 horas. Após esta etapa, $5 \mu \mathrm{l}$ foram inoculados em placas de microdiluição contendo $195 \mu \mathrm{l}$ de TSB e as placas foram incubadas por 24 horas a $37^{\circ} \mathrm{C}$ sob agitação (50 rpm). Após este período, o conteúdo de cada poço foi aspirado cuidadosamente e este foi lavado duas vezes com PBS $1 \mathrm{x}$ estéril, para remoção de células livres (planctônicas). As placas foram deixadas em temperatura ambiente até a secagem, onde as células aderidas eram então coradas com violeta de genciana a 0,25\%. Após 5 minutos da aplicação do corante, os poços foram novamente lavados, como descrito anteriormente, e submetidos a secagem em temperatura ambiente. 0 que restou na placa foi ressuspendido em álcool:acetona na proporção 80:20. Em cada placa utilizou-se um poço contendo somente TSB como controle negativo. A leitura foi realizada por espectofotometria no aparelho SpectraMax M5 a $495 \mathrm{~nm}$. Para classificar os isolados quanto à produção de biofilme, mediu-se a D0495 do controle negativo (DOcn) e comparou-se com a D0495 dos isolados (DOis). Os isolados foram classificados como fracos (DOcn<DOis $<2$. DOcn), moderados (2.DOcn<DOis<4.DOcn) ou fortes (4.DOcn<DOis).

Preparo dos isolados de Staphylococcus spp. para avaliação dos desinfetantes. Os isolados de Staphylococcus spp. foram semeados em TSB com $1 \%$ de glicose e incubados a $37^{\circ} \mathrm{C}$ por 24 horas. Após a incubação, a concentração bacteriana foi ajustada para $5 \times 10^{7} \mathrm{UFC} / \mathrm{ml}$ através de diluições em TSB e medições da densidade óptica. A concentração bacteriana utilizada constitui o desafio recomendado pelo National Mastitis Council para protocolos de avaliação de eficácia de produtos pós-dipping (National Mastitis Council 2004).

Produtos testados. Foram testados dois produtos disponíveis comercialmente: a base de clorexidine a $2 \%$ (Globovac, Porto Alegre, Brasil) e iodo a 0,7\% (Tadabras, Bragança Paulista, Brasil), indicados para aplicação nos tetos após a ordenha. Segundo as normas dos fabricantes, ambos os produtos são prontos para o uso, sem a necessidade de diluições.

Ação dos desinfetantes sobre a adesão de Staphylococcus spp. A avaliação dos desinfetantes sobre a adesão dos isolados de Staphylococcus spp. analisados seguiu a metodologia descrita por Pagano et al. (2004), com pequenas adaptações, como a substituição de placas de 96 poços por placas de 24 poços. Foram destinados dois poços para cada isolado. No primeiro poço, denominado controle positivo, a suspensão foi constituída de meio TSB com $1 \%$ de glicose $(1,2 \mathrm{ml})$ e do inoculo $(0,1 \mathrm{ml})$. No segundo poço realizou-se o mesmo procedimento acrescentando-se ainda o desinfetante a ser testado $(0,8 \mathrm{ml})$. 0 procedimento foi realizado em triplicata. Cada placa continha ainda um controle negativo com apenas o meio TSB. As placas foram incubadas por 24 horas a $37^{\circ} \mathrm{C}$ sob agitação (50 rpm). Após este período, o conteúdo de cada poço foi aspirado cuidadosamente e este foi lavado duas vezes com PBS 1x estéril, para remoção de células livres (planctônicas). As placas foram deixadas em temperatura ambiente até a secagem, onde as células aderidas foram então coradas com violeta de genciana a $0,25 \%(0,3 \mathrm{ml})$. Após 5 minutos da aplicação do corante, os poços foram novamente lavados, por duas vezes com PBS, e submetidos à secagem em temperatura ambiente. 0 que restou na placa foi ressuspendido em álcool:acetona na proporção 80:20 (0,3 ml). 0 efeito dos desinfetantes sobre a adesão das células foi medido por espectrofotometria no aparelho SpectraMax M5 a $495 \mathrm{~nm}$. Testes piloto foram conduzidos a fim de determinarmos o comprimento de onda ideal (dados não mostrados). Para compensar a absorbância medida a partir dos desinfetantes e do meio TSB, leituras de densidade óptica (DO) foram realizadas em poços contendo apenas iodo com TSB e clorexidine com TSB, nas mesmas proporções acima citadas. Os valores de DO obtidos 
foram então descontados das leituras realizadas nos poços com desinfetante, meio e inóculo bacteriano. Antes da adição do corante, alíquotas de $10 \mu \mathrm{l}$ de cada poço tratado foram semeadas em TSA a fim de verificarmos se as concentrações dos desinfetantes testadas apresentavam capacidade bactericida sobre os isolados Staphylococcus spp. analisados, na forma planctônica.

Ação dos desinfetantes sobre biofilme consolidado. Essa segunda etapa da pesquisa procedeu-se de forma semelhante à primeira. Também foram destinados dois poços para cada amostra, com a suspensão constituída de meio TSB com 1\% de glicose $(1,2 \mathrm{ml})$ e do inoculo $(0,1 \mathrm{ml})$, em placas de 24 poços incubadas por 24 horas a $37^{\circ} \mathrm{C}$ sob agitação $(50 \mathrm{rpm})$, porém, sem a aplicação do desinfetante em um primeiro momento. Após a incubação e obtenção de películas características de formação de biofilme, o meio foi aspirado cuidadosamente e realizaram-se duas lavagens com PBS 1x estéril em todos os poços. Após a secagem à temperatura ambiente, pode-se visualizar a formação de biofilme no fundo de cada poço, estando estes apropriados para a etapa seguinte. A seguir, aplicou-se TSB com 1\% de glicose em ambos os poços $(1,2 \mathrm{ml})$ e o desinfetante somente no segundo poço. As placas foram novamente incubadas por mais 24 horas nas mesmas condições anteriores. Após esse período, realizou-se duas lavagens, com PBS 1x estéril, seguido de secagem à temperatura ambiente, e então os poços foram corados com violeta de genciana a $0,25 \%$ (0,3 ml). Após 5 minutos da aplicação da violeta de genciana, os poços foram novamente lavados, por duas vezes com PBS, e submetidos à secagem novamente. 0 que restou na placa foi ressuspendido em álcool:acetona na proporção 80:20 (0,3 ml). 0 efeito dos desinfetantes sobre os biofilmes formados foi medido por espectofotometria no aparelho SpectraMax M5 a 495nm. Antes da adição do corante, alíquotas de $10 \mu \mathrm{l}$ de cada poço tratado foram semeadas em TSA a fim de verificarmos se as concentrações dos desinfetantes testadas apresentavam capacidade bactericida sobre os isolados de Staphylococcus spp. analisados, na forma séssil.

Critérios interpretativos. A interpretação dos valores de adesão foi realizada conforme Pagano et al. (2004). Valores de D0495 acima da D0 observada nos controles com desinfetante mais TSB foram considerados como valores indicativos de aderência bacteriana. 0 cálculo de porcentagem de inibição de adesão foi realizado para todos os isolados que apresentaram aderência, sendo a seguinte formula utilizada: \% de adesão = (DO do poço controle - DO do poço tratado/DO do poço controle) x 100. Sendo a DO representada pela média das triplicatas e o controle definido por cultivo livre de desinfetante.

Análise estatística. A homogeneidade das variâncias entre os grupos foi verificada através do teste de Levene. As comparações entre os grupos foram realizadas utilizando ANOVA de uma via seguida do teste de Tukey (Statistica 7.0 Software). 0 nível mínimo de significância foi estabelecido em $\mathrm{P} \leq 0,05$.

\section{RESULTADOS}

\section{Caracterização dos isolados quanto à produção de bio-} filmes

Todos os isolados foram caracterizados como produtores de biofilme. Em relação à intensidade de formação, tanto os SCP, como os SCN foram classificados como fortes formadores de biofilme, uma vez que, apresentaram DO acima de no mínimo quatro vezes a DO do seu respectivo controle.

\section{Ação dos desinfetantes sobre a adesão de Staphylococ- cus spp.}

Do total de isolados de Staphylococcus spp. analisados $(\mathrm{n}=16), 14$ (87,5\%, sete SCP e sete SCN) e 12 isolados $(75 \%$,
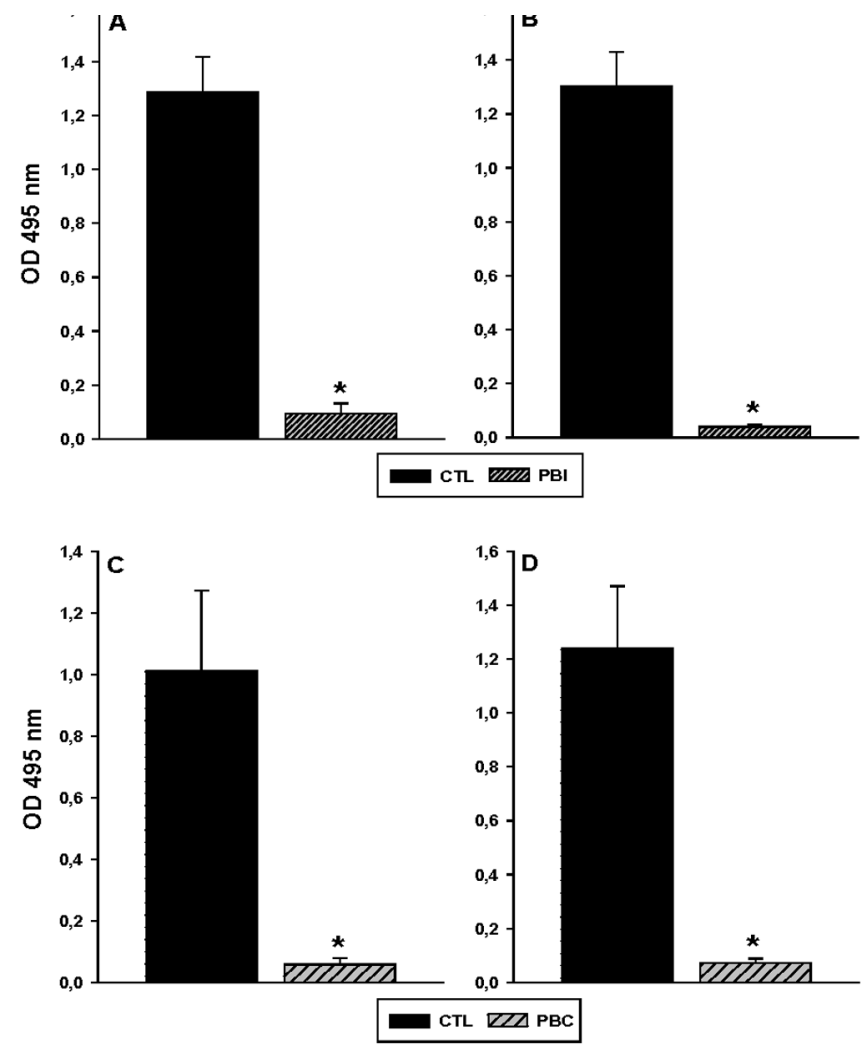

Fig.1. Atividade de produtos a base de iodo (A e B) e clorexidine (C e D) sobre a adesão de SCN (A e C) e SCP (B e D). CTL = controle; $\mathrm{PBI}=$ produto a base de iodo $\mathrm{PBC}=$ produto a base de clorexidine. * Indica diferença significativa em relação ao respectivo controle, conforme determinado por ANOVA de uma via seguida do teste de Tukey $(\mathrm{P} \leq 0,05)$.

oito SCP e quatro SCN) apresentaram capacidade de adesão mesmo quanto expostos aos produtos a base de clorexidine $(2 \%)$ e iodo $(0,7 \%)$, respectivamente. No entanto, quando comparado ao controle, observou-se redução significativa da adesão em todos os isolados submetidos aos desinfetantes (Fig.1). A taxa percentual de redução da adesão foi de 92,8 a $97 \%$. O produto a base de iodo inibiu em 92,8 e $97 \%$ a adesão de células de SCP e SCN, respectivamente. Já o produto a base de clorexidine apresentou a mesma atividade em ambos os grupos de Staphylococcus spp., com 94,3\% de redução. Como era esperado, não foram recuperadas bactérias viáveis apos às 24 horas de exposição aos desinfetantes.

\section{Ação dos desinfetantes sobre biofilme consolidado}

Tanto o clorexidine $(2 \%)$ quanto o iodo $(0,7 \%)$ apresentaram redução significativa sobre o biofilme formado por SCN (Fig.2), sendo esta de 36,7\% após exposição ao clorexidine e $32,5 \%$ ao iodo. Frente aos isolados de SCP, não observou-se redução significativa em comparação com o grupo controle (Fig.2). Após a semeadura em TSA, todos os isolados testados apresentaram crescimento após 24 horas de exposição aos desinfetantes.

\section{DISCUSSÃO}

Muitos estudos têm avaliado a concentração inibitória mínima (CIM) de agentes antimicrobianos, relacionando-a com 

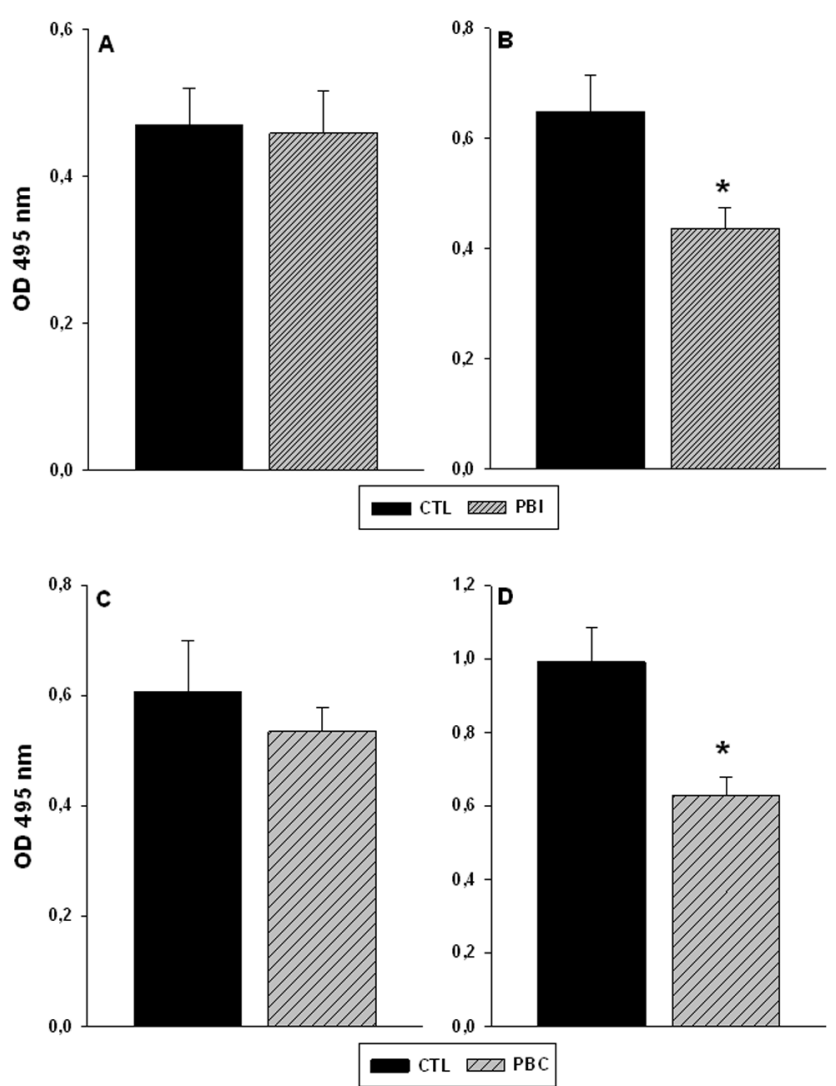

Fig.2. Atividade de produtos a base de iodo (A e B) e clorexidine (C e D) sobre biofilme consolidado de SCP (A e C) e SCN (B e D). $\mathrm{CTL}=$ controle $\mathrm{PBI}=$ produto a base de iodo $\mathrm{PBC}=$ produto $\mathrm{a}$ base de clorexidine. * Indica diferença significativa em relação ao respectivo controle, conforme determinado por ANOVA de uma via seguida do teste de Tukey $(\mathrm{P} \leq 0,05)$.

a CIM necessária para impedir a adesão bacteriana e formação de biofilme ou até mesmo, a ação sob micro-organismos em biofilme consolidado (Pagano et al. 2004). Para o nosso conhecimento, este é o primeiro estudo avaliando a ação de produtos a base de clorexidine $(2 \%)$ e iodo $(0,7 \%)$ sobre a adesão e biofilme consolidado de SCP e SCN. Como as concentrações de clorexidine $2 \%$ e iodo $0,7 \%$ são conhecidamente eficazes contra células livres de Staphylococcus spp. (Pedrini \& Margatho 2003), não era esperada a recuperação de células viáveis após 24 horas de exposição aos desinfetantes, porém, até a realização deste estudo, não se sabia se estas concentrações seriam capazes de prevenir a adesão das células.

No presente estudo, observou-se que $87,5 \%$ e $75 \%$ dos isolados analisados foram capazes de se aderir à superfície de polipropileno sob a ação do clorexidine e do iodo, respectivamente. No entanto, houve uma redução de 92,8 a $97 \%$ na adesão quanto comparada ao grupo controle (Fig.1). Acreditamos que este resultado seja importante para prevenção de casos de mastite. Galton (2004) observou uma redução de $64,5 \%$ de novos casos de mastite por S. aureus em quartos mamários submetidos ao pós-dipping com produto a base de iodo, o que pode ser explicado pela forte ação dos produtos utilizados, já que a maior parte das infecções pode ser evitada se a adesão de micro-organismos patogênicos não ocorrer (Pagano et al. 2004).
Apesar dos produtos a base de iodo e clorexidine serem amplamente utilizados no tratamento de infecções superficiais de tetos em vacas, e este último apresentar efeito antibacteriano cumulativo de no mínimo seis horas (Spinosa et al. 2002), o processo de adesão de Staphylococcus sp. é muito rápido, menos de três horas (Millezi et al. 2012), especialmente em condições favoráveis. As condições empregadas in vitro, neste estudo, como a adição de glicose ao meio de cultura, podem ter favorecido a adesão dos isolados analisados. A glicose, pela alteração de pH, é um importante fator ambiental associado à formação de biofilme em S. epidermidis através da regulação de proteínas via expressão de genes como o saeRS (Lou et al. 2014). Sabe-se que a presença de dextrano, que consiste de unidades de $\alpha$-Dglicose, é fundamental para a adesão de isolados de Streptococcus spp. (Thompson et al. 1982). Estes dados podem explicar, em parte, a aderência dos isolados de Staphylococcus spp., mesmo que não tenham sido recuperadas células viáveis apos 24 horas de exposição aos desinfetantes.

A presença de proteínas é um fator muito importante para formação de biofilme por $S$. epidermidis (Lou et al. 2014). Segundo Varhimo et al. (2011), alfa e beta-caseína são indutores primários para a formação de biofilme, a qual inicia-se com a adesão a uma superfície, seja ela biótica ou abiótica (Hall-Stoodley \& Stoodley 2002). Considerando que após a ordenha o teto encontra-se sujeito a deposição destas proteínas, e estas favorecem a formação de biofilme, salientamos a importância de avaliar produtos utilizados no pós-dipping quanto a sua capacidade de impedir a adesão de células bacterianas, bem como, sua ação sobre biofilme consolidado.

Sabe-se que células em biofilmes são muito mais resistentes à desinfecção quando comparadas às células planctônicas, desta forma, muitos métodos convencionais de desinfecção são ineficientes contra biofilmes, sendo necessário, por vezes, doses elevadas (Clonts 2008). Neste estudo, os isolados de Staphylococcus spp. presentes no biofilme consolidado apresentaram uma forte resistência, sendo que células viáveis foram recuperadas após 24 horas de exposição aos desinfetantes analisados. Segundo Marques et al. (2007), S. aureus na forma de biofilme se torna mais resistente aos agentes sanificantes. Esta resistência está associada tanto à baixa penetração dos compostos antimicrobianos no biofilme, como pelo estado fenotipicamente protegido, induzido nas bactérias que o compõe (Costerton et al. 1995, Altieri et al. 2013). Por fim, sua estabilidade deve-se a proteínas e carboidratos (Wang et al. 2013), que, uma vez depositados, dificultam em muito a ação de compostos sanificantes e antimicrobianos.

Muitos desinfetantes apresentam ação em suspensões microbianas, porém, sobre biomassas a atividade diminui muito, o que pode ser explicado pelo desenvolvimento de formas de resistência por parte do biofilme (Pereira 2001). Esta maior resistência foi verificada nos SCP, uma vez que, frente aos desinfetantes analisados, praticamente não se observou redução da biomassa (Fig.2). No entanto, tanto o clorexidine quanto o iodo, apresentaram um efeito significativo na redução do biofilme formado por SCN (Fig.2). Isso pode ser explicado pela menor virulência apresentada por 
estes isolados, que geralmente causam mastites mais brandas, nas quais os animais respondem bem ao tratamento (Pyorala \& Taponen 2009). Salientamos a importância da utilização de desinfetantes no pós-dipping na prevenção da adesão bacteriana, com intuito de retardar a formação do biofilme, uma vez que, eliminar ou reduzir a biomassa bacteriana e extremamente difícil. Por fim, este estudo reforça a importância da inclusão de estratégias de controle sanitário para prevenção da mastite bovina, tendo em vista que o contato dos animais com patógenos contagiosos durante o processo de ordenha é praticamente inevitável.

\section{CONCLUSÕES}

Os produtos a bases de clorexidine $(2 \%)$ e iodo $(0,7 \%)$ não foram capazes de inibir a adesão da maioria dos isolados analisados, no entanto apresentaram-se altamente eficazes na sua redução.

Ambos os desinfetantes apresentam ação insatisfatória sobre biofilme consolidado de Staphylococcus spp., especialmente frente aos SCP.

Ressalta-se a importância do estabelecimento de programas sanitários a fim de prevenir a formação de biofilmes e a diminuição das fontes de contaminação da glândula mamária nos diferentes sistemas de produção leiteira.

\section{REFERÊNCIAS}

Altieri K.T., Sanita P.V., Machado A.L., Giampaolo E.T., Pavarina A.C., Jorge J.H. \& Vergani C.V. 2013. Eradication of a mature methicillin-resistant Staphylococcus aureus (MRSA) biofilm from acrylic surfaces. Braz. Dent. J. 24(5):487-449.

Amaral L.A., Isa H., Dias L.T., Rossi O.D. \& Filho N.F. 2004. Avaliação da eficiência da desinfecção de teteiras e dos tetos no processo de ordenha mecanica de vacas. Pesq. Vet. Bras. 24:173-177.

Barlow J. 2011. Mastitis Therapy and Antimicrobial Susceptibility: a multispecies review with a focus on antibiotic treatment of mastitis in dairy cattle. J. Mammary Gland Biol. Neoplasia 16:383-407.

Boddie R.L. \& Nickerson S.C. 2002. Reduction of mastitis caused by experimental challenge with Staphylococcus aureus and Streptococcus agalactiae by use of a quaternary ammonium and halogen- mixture teat dip. J. Dairy Sci. 85:258-262.

Clonts L. 2008. Como evitar a formação de biofilmes. Revta Controle de Contaminação 109:50-56.

Costerton J.W., Lewandowski Z., Caldwell D.E., Korber D.R. \& Lappin-Scott H.M. 1995. Microbial biofilms. Annu. Rev. Microbial. 49:711-745.

Edinger D., Tenhagen B.A., Kalbe P., Klunder G., Baumgartner B. \& Heuwieser W. 2000. Effect of Teat Dipping with a Germicide Barrier Teat Dip in Late Gestation on Intramammary Infection and Clinical Mastitis during the First 5 Days Post-partum in Primiparous Cows. J. Vet. Med. 47:463-468.

Galton D.M. 2004. Effects of an automatic postmilking teat dipping system on new intramammary infections and iodine in milk. J. Dairy Sci. 87:225-231.

Hall-Stoodley L. \& Stoodley P. 2002. Developmental regulation of microbial biofilms. Curr. Opinion Biotechnol. 13:228-233.

Lou Q., Qi Y., Ma Y. \& Qu D. 2014. Two-component signal transduction system SaeRS positively regulates Staphylococcus epidermidis glucose metabolism. Scient. World J. 2014:1-12.

MacFaddin J.F. 2000. Biochemical Testes for Identification of Medical Bacteria. $3^{\text {rd }}$ ed. Lippincott Williams and Wilkins, Philadelphia, p.105-117.

Marques S.C., Rezende J.G.O.S., Alves L.A.F., Silva B.C., Alves E., Abreu L.R. \& Piccoli R.H. 2007. Formation of biofilms by Staphylococcus aureus on stainless steel and glass surfaces and its resistance to some selected chemical sanitizers. Braz. J. Microbiol. 38:538-543.
Medeiros E.S., Santos M.V., Pinheiro J.W.J., Faria E.B., Wanderley G.G., Teles J.A.A. \& Mota R.A. 2009. Avaliação in vitro da eficácia de desinfetantes comerciais utilizados no pré e pós-dipping frente amostras de Staphylococcus spp. isoladas de mastite bovina. Pesq. Vet. Bras. 29(1):71-75.

Millezi F.M., Pereira M.O., Batista N.N., Camargos N., Auad I., Cardoso M.D.G. \& Piccoli R.H. 2012. Susceptibility of monospecies and dual species biofilms of Staphylococcus aureus and Escherichia coli to essential oils. J. Food Safety 32:351-359.

National Mastitis Council 2004. Recomended protocols for evaluating efficacy of postmilking teat germicides. Proc. NMC Annual Meeting, p.280.

Oliveira M., Bexiga R., Nunes S.F., Carneiro C., Cavaco L.M., Bernardo F. \& Vilela C.L. 2006. Biofilm-forming ability profiling of Staphylococcus aureus and Staphylococcus epidermidis mastitis isolates. Vet. Microbiol. 118:133-140.

Otto M. 2008. Staphylococcal Biofilms. Curr. Topics Microbiol. Immunol. 322:207-228.

Pagano P.J., Buchanan L.V., Dailey C.F., Haas J.V., Van Enkb R.A. \& Gibson J.K. 2004. Effects of linezolid on staphylococcal adherence versus time of treatment. Int. J. Antimicrob. Agents 23:226-234.

Pedrini S.C.B. \& Margatho L.F.F. 2003. Sensibilidade de micro-organismos patogênicos isolados de casos de mastite clínica em bovinos frente a diferentes tipos de desinfetantes. Arq. Inst. Biológico, São Paulo, 70:391395.

Pereira M.O.B.O. 2001. Comparação da eficácia de dois biocidas (Carbamato e Glutaraldeido) em sistemas de biofilmes. Tese de Doutorado, Universidade do Minho, Braga. 234p.

Pyorala S. \& Taponen S. 2009. Coagulase-negative staphylococci: emerging mastitis pathogens. Vet. Microbiol. 134:3-8.

Quinn P.J. 1994. Corynebacterium species and Rhodococcus equi, p.137143. In: Quinn P.J., Carter M.E., Markey B.K. \& Carter G.R. (Eds), Clinical Veterinary Microbiology. Wolfe Publ., London.

Ramalho A.C., Soares K.D.A., Silva D.F., Barros M.R.C., Pinheiro J.W.J., Oliveira J.M.B., Mota R.A. \& Medeiros E.S. 2012. Eficácia in vitro de desinfetantes comerciais utilizados no pre e pós-dipping frente a Staphylococcus spp. isolados em rebanhos leiteiros. Pesq. Vet. Bras. 32(12):1285-1288.

Rodrigues L.B., Santos L.R., Tagliari V.Z., Rizzo N.N., Trenhago G., Oliveira A.P., Goetz F. \& Nascimento V.P. 2010. Quantification of biofilm production on polysturene by Listeria, Escherichia coli and Staphylococcus aureus isolated from a poultry slaughterhouse. Braz. J. Microbiol. 41:10821085.

Sá M.E.P., Cunha M.L.R.S., Elias A.O. \& Langoni C.V.H. 2004. Importância de Staphylococcus aureus nas mastites subclínicas: pesquisa de enterotoxinas e toxina do choque tóxico, e a relação com a contagem de células somáticas. Braz. J. Vet. Res. Anim. Sci. 41:320-326.

Santos M.V. \& Fonseca L.F.L. 2007. Estratégias para o controle de mastites e melhoria da qualidade do leite. Manole, Barueri/SP, p.47-64.

Spinosa H.S., Gorniak S.L. \& Bernardi M.M. 2002. Farmacologia Aplicada à Medicina Veterinária. Guanabara-Koogan, Rio de Janeiro, p.389-394.

Stepanovic S., Vukovic D., Hola V., Bonaventura G., Djukic S., Cirkovic I. \& Ruzicka F. 2007. Quantification of biofilm in microtiter plates: overview of testing conditions and pratical recommendations for assessment of biofilm production by staphylococci. APMIS 115:891-899.

Thompson J., Meddens M.J.M., Thorig L. \& Van Furth R. 1982. The Role of Bacterial Adherence in the Pathogenesis of Infective Endocarditis. Infection 10(3):196-198.

Varhimo E., Varmanen P., Fallarero A., Skogman M., Pyorala S., Iivanainen A., Sukura A., Vuorela P. \& Savijoki K. 2011. Alpha- and $\beta$-casein components of host milk induce biofilm formation in the mastitis bacterium Streptococcus uberis. Vet. Microbiol. 149:381-389.

Vermelho A.B., Bastos M.C.F.B. \& Sa M.H.B. 2007. Bacteriologia Geral. Guanabara Koogan, Rio de Janeiro, p.50.

Wang H., Ding S., Wang G., Xu X. \& Zhou G. 2013. In situ characterization and analysis of Salmonella biofilm formation under meat processing environments using a combined microscopic and spectroscopic approach. Int. J. Food Microbiol. 167:293-302 